ISSN 1996-1944

www.mdpi.com/journal/materials

Article

\title{
Crystal Growth and Spectroscopic Investigations of $\mathrm{Tm}^{3+}: \mathrm{Li}_{3} \mathrm{Ba}_{2} \mathbf{G d}_{3}\left(\mathrm{MoO}_{4}\right)_{8}$ Crystal
}

Mingjun Song ${ }^{1, *}$, Lintong Wang ${ }^{1}$, Nana Zhang ${ }^{1}$, Xishi Tai ${ }^{1}$ and Guofu Wang ${ }^{2}$

1 School of Chemistry and Chemical Engineering, Weifang University, Weifang 261061, Shandong, China; E-Mails: wanglt6408@sina.com (L.W.); zhangnana0801@126.com (N.Z.); taixs@wfu.edu.cn (X.T.)

2 Fujian Institute of Research on the Structure of Matter, The Chinese Academy of Sciences, Fuzhou 350002, Fujian, China; E-Mail: wgf@fjirsm.ac.cn

* Author to whom correspondence should be addressed; E-Mail: smj521@hotmail.com; Tel.: +86-536-8785-283; Fax: +86-536-8785-136.

Received: 3 October 2013; in revised form: 11 December 2013 / Accepted: 17 December 2013 / Published: 17 January 2014

\begin{abstract}
Tm}^{3+}: \mathrm{Li}_{3} \mathrm{Ba}_{2} \mathrm{Gd}_{3}\left(\mathrm{MoO}_{4}\right)_{8}$ crystal has been grown by the top seeded solution growth (TSSG) method from a $\mathrm{Li}_{2} \mathrm{MoO}_{4}$ flux. The room temperature polarized absorption spectra, fluorescence spectra, and fluorescence decay curves of the crystal were measured. Based on the Judd-Ofelt (J-O) theory, the main spectroscopic parameters of the crystal, including the spontaneous emission probabilities, fluorescence branching ratios, and radiative lifetimes were calculated and analyzed. The broad and strong absorption bands of the crystal show that it can be efficiently pumped by the diode laser, while the large emission cross-sections of the ${ }^{3} \mathrm{~F}_{4} \rightarrow{ }^{3} \mathrm{H}_{6}$ transition indicate that the crystal is a promising candidate for tunable and short pulse lasers.
\end{abstract}

Keywords: crystal growth; optical materials; spectral properties; cross section

\section{Introduction}

With the rapid progress of high power diode lasers, $\mathrm{Tm}^{3+}$-doped laser media has been intensively investigated because of their potential applications associated with emissions in the visible and infrared spectral regions, particularly at $\sim 1.50$ and $\sim 2.0 \mu \mathrm{m}$ wavelength. As we know, the ${ }^{3} \mathrm{~F}_{4} \rightarrow{ }^{3} \mathrm{H}_{6}$ transition of $\mathrm{Tm}^{3+}$ ions is one of the most effective channels for the development of $2.0 \mu \mathrm{m}$ lasers, which have 
many important applications in fields of medicine, gas detection, remote sensing, etc. On the other hand, the ${ }^{3} \mathrm{H}_{4} \rightarrow{ }^{3} \mathrm{~F}_{4}$ transition of $\mathrm{Tm}^{3+}$ ions gives rise to an additional infrared emission band around $1.5 \mu \mathrm{m}$, where applications such as detection, ranging and optical communication have been found. Other important advantages of $\mathrm{Tm}^{3+}$ ions include strong absorption of AlGaAs diode laser radiation at $\sim 800 \mathrm{~nm}$, a long lifetime of the ${ }^{3} \mathrm{~F}_{4}$ state, a high quantum efficiency due to the cross-relaxation between ${ }^{3} \mathrm{H}_{4}$ and ${ }^{3} \mathrm{~F}_{4}$ multiplets, as well as a wide emission band around in the range of 1800-2000 nm, which is definitely promising for the generation of tunable and ultrafast solid state lasers. To date, efficient laser operations around $2.0 \mu \mathrm{m}$ have been realized in a number of $\mathrm{Tm}^{3+}$-doped crystals [1-10].

Among the reported crystals, the double tungstate and molybdate crystals with scheelite structure are characterized by their local disordered crystal structure [4-8]. The advantages of these crystals are high quantum efficiency, broad absorption and emission brands, as well as relatively low upper-level lifetime. Furthermore, such a combination of these merits is very promising for generations of tunable and ultra fast lasers. More recently, a new series of disordered molybdate compounds $\mathrm{Li}_{3} \mathrm{Ba}_{2} \mathrm{Re}_{3}\left(\mathrm{MoO}_{4}\right)_{8}(\mathrm{Re}=\mathrm{La}-\mathrm{Lu}, \mathrm{Y})$, which belong to the monoclinic system, with the space group $\mathrm{C} 2 / \mathrm{c}$, have emerged as new kinds of laser materials, especially in tunable and ultrafast laser domains [11-17]. The structure of $\mathrm{Li}_{3} \mathrm{Ba}_{2} \mathrm{Re}_{3}\left(\mathrm{MoO}_{4}\right)_{8}$ can also be considered to be derived from the scheelite structure, in which the $\mathrm{Ca}^{2+}$ sites are occupied by a statistical mixture of $25 \% \mathrm{Ba}^{2+}, 37.5 \% \mathrm{Li}^{+}$, and $37.5 \% \mathrm{Re}^{3+}[13]$. Consequently, rare earth doped $\mathrm{Li}_{3} \mathrm{Ba}_{2} \mathrm{Re}_{3}\left(\mathrm{MoO}_{4}\right)_{8}$ crystals usually exhibit very similar spectral properties to the typical disordered double molybdate crystals. Up to now, efficient laser operation has already been realized in $\mathrm{Nd}^{3+}$ and $\mathrm{Yb}^{3+}$-doped $\mathrm{Li}_{3} \mathrm{Ba}_{2} \mathrm{Gd}_{3}\left(\mathrm{MoO}_{4}\right)_{8}$ crystals [11,13]. Not long ago, Zaldo et al. [16] have demonstrated the great potential of $\mathrm{Tm}^{3+}: \mathrm{Li}_{3} \mathrm{Ba}_{2} \mathrm{Lu}_{3}\left(\mathrm{MoO}_{4}\right)_{8}$ crystal for tunable and ultrashort pulse lasers around $2 \mu \mathrm{m}$, i.e., a tunable laser in the range of 1853-2009 nm, with a slope efficiency up to $71 \%$, higher than those obtained in disordered crystals so far, has been obtained with a Ti:laser as pump source. Furthermore, the large free running laser bandwidth indicated that the $\mathrm{Tm}^{3+}: \mathrm{Li}_{3} \mathrm{Ba}_{2} \mathrm{Lu}_{3}\left(\mathrm{MoO}_{4}\right)_{8}$ crystal is definitely promising for generations of ultrafast laser pulses. In the present work, the studies are extended to $\mathrm{Tm}^{3+}$-doped $\mathrm{Li}_{3} \mathrm{Ba}_{2} \mathrm{Gd}_{3}\left(\mathrm{MoO}_{4}\right)_{8}$ crystal with the objective of exploring new $\mathrm{Tm}^{3+}$-doped crystal for efficient laser operations near $2 \mu \mathrm{m}$, and the growth and spectral properties of $\mathrm{Tm}^{3+}: \mathrm{Li}_{3} \mathrm{Ba}_{2} \mathrm{Gd}_{3}\left(\mathrm{MoO}_{4}\right)_{8}$ crystal are reported.

\section{Experimental Section}

\subsection{Crystal Growth and Orientation}

As $\mathrm{Li}_{3} \mathrm{Ba}_{2} \mathrm{Gd}_{3}\left(\mathrm{MoO}_{4}\right)_{8}$ crystal melts incongruently [12], the crystal was grown by the top seeded solution growth (TSSG) method from a flux of $\mathrm{Li}_{2} \mathrm{MoO}_{4}$. The solubility curve of $\mathrm{Li}_{3} \mathrm{Ba}_{2} \mathrm{Gd}_{3}\left(\mathrm{MoO}_{4}\right)_{8}$ crystal in the $\mathrm{Li}_{3} \mathrm{Ba}_{2} \mathrm{Gd}_{3}\left(\mathrm{MoO}_{4}\right)_{8}-\mathrm{Li}_{2} \mathrm{MoO}_{4}$ solution can be found in Reference [14]. The crystal growth was carried out in a vertical tubular muffle furnace with a nickel-chrome wire as the heating element. An AL-708 apparatus controlled the furnace temperature and the rate of cooling. The starting materials, 3 at $\% \mathrm{Tm}^{3+}$-doped $\mathrm{Li}_{3} \mathrm{Ba}_{2} \mathrm{Gd}_{3}\left(\mathrm{MoO}_{4}\right)_{8}$ and $\mathrm{Li}_{2} \mathrm{MoO}_{4}$ were weighed, with a molar ratio of $\mathrm{TmLi}_{3} \mathrm{Ba}_{2} \mathrm{Gd}_{3}\left(\mathrm{MoO}_{4}\right)_{8}: \mathrm{Li}_{2} \mathrm{MoO}_{4}=1: 4$. A single-crystalline bar cut along $b$-direction was used to introduce crystal nucleation. The growth temperature interval was $900-870{ }^{\circ} \mathrm{C}$, with a cooling rate of $1{ }^{\circ} \mathrm{C} / \mathrm{d}$ and a rotating rate of $12 \mathrm{rpm}$. Additional details on crystal growth can be found 
in Reference $[14,15]$. The as-grown $\mathrm{Tm}^{3+}: \mathrm{Li}_{3} \mathrm{Ba}_{2} \mathrm{Gd}_{3}\left(\mathrm{MoO}_{4}\right)_{8}$ crystal with a prism shape is shown in Figure 1a. The initial dimension of the grown crystal is about $15 \times 10 \times 40 \mathrm{~mm}^{3}$ along the $a, b$, and $c$-directions, respectively. However, due to the cleavable nature of the crystal, the grown crystal has split along the middle along the cleavage plane (001) during the annealing process. As a result, only a small part of the obtained crystal is shown in Figure 1a. Figure 1b shows the morphological scheme of the grown crystal. The rectangular facets on the top and bottom of the crystal were established to be (010) and (0-10) faces, respectively, which are consistent with those of the $\mathrm{Li}_{3} \mathrm{Ba}_{2} \mathrm{Lu}_{3}\left(\mathrm{MoO}_{4}\right)_{8}$ crystal [17]. However, different from the $\mathrm{Li}_{3} \mathrm{Ba}_{2} \mathrm{Lu}_{3}\left(\mathrm{MoO}_{4}\right)_{8}$ crystal, the facets along sides of the crystal were identified to be (110) and (-110) faces, respectively, rather than $(100)$ and $(-100)$ faces. As a consequence, the grown crystal possesses a trapezoid cross-section, as shown in Figure 1c. It can be found that the profile of the (00-1) face of the $\mathrm{Tm}^{3+}: \mathrm{Li}_{3} \mathrm{Ba}_{2} \mathrm{Gd}_{3}\left(\mathrm{MoO}_{4}\right)_{8}$ crystal is in good accordance with that of the $\mathrm{Yb}^{3+}: \mathrm{Li}_{3} \mathrm{Ba}_{2} \mathrm{Gd}_{3}\left(\mathrm{MoO}_{4}\right)_{8}$ and $\mathrm{Er}^{3+}: \mathrm{Li}_{3} \mathrm{Ba}_{2} \mathrm{Y}_{3}\left(\mathrm{MoO}_{4}\right)_{8}$ crystal grown along the $a$-direction $[12,15]$.

Figure 1. (a) Grown crystal of $\mathrm{Tm}^{3+}: \mathrm{Li}_{3} \mathrm{Ba}_{2} \mathrm{Gd}_{3}\left(\mathrm{MoO}_{4}\right)_{8}$; (b) The morphological scheme of the crystal; (c) Cross-section of the as grown crystal.
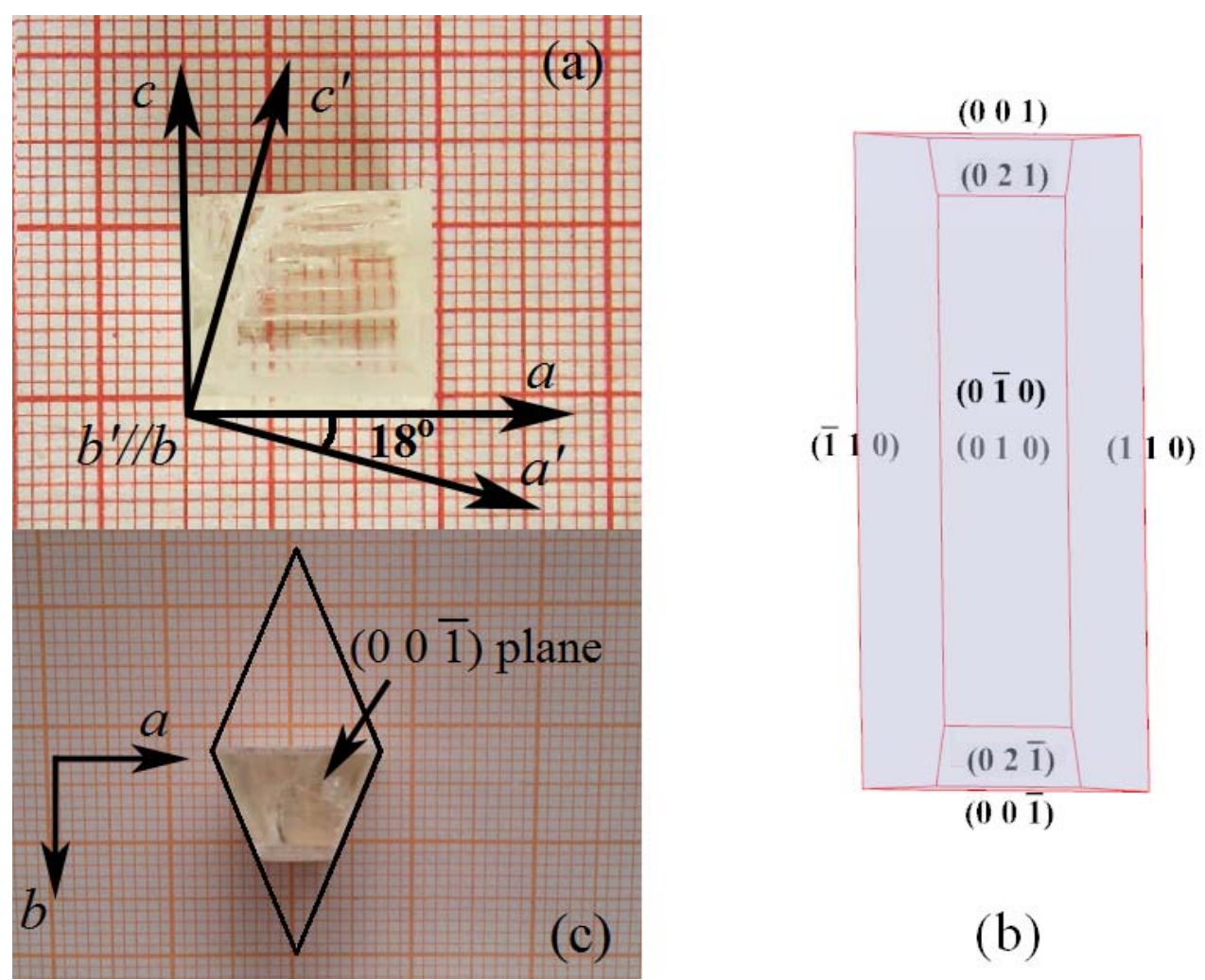

As the $\mathrm{Li}_{3} \mathrm{Ba}_{2} \mathrm{Gd}_{3}\left(\mathrm{MoO}_{4}\right)_{8}$ crystal is biaxial, the three principal axes of the optical indicatrix should be determined before the polarized spectral measurement. In the monoclinic system, one of the principal axes is collinear with the crystallographic $b$-axis and the other two principal axes are perpendicular and positioned at certain angles with respect to crystallographic $a$ and $c$-axes. Then, the other two principal axes can be easily determined when the sample is viewed along the $b$-axis direction under a polarized microscope. However, due to the restriction of the test conditions, the precise values of the refractive index for the three principal axes were not measured. As the cell parameters and the 
positions of the three principal axes relative to the crystallographic axes are very close to the $\mathrm{Li}_{3} \mathrm{Ba}_{2} \mathrm{Lu}_{3}\left(\mathrm{MoO}_{4}\right)_{8}$ crystal, the three principal axes are temporarily named in the same way as the $\mathrm{Li}_{3} \mathrm{Ba}_{2} \mathrm{Lu}_{3}\left(\mathrm{MoO}_{4}\right)_{8}$ crystal [16,17]. As shown in Figure 1a, the principal axis collinear with the crystallographic $b$ axis is named as $b^{\prime} ; a^{\prime}$ is rotated at $18^{\circ}$ with respect to $a$ axis in the clockwise direction as the crystals are viewed from the negative $b$ axis, finally, $c^{\prime}$ is perpendicular to $a^{\prime}$ and $b^{\prime}$.

\subsection{Characterizations}

The polarized absorption spectra were measured using a Perkin-Elmer UV-VIS-NIR spectrometer (Lambda-900) in a wavelength range of 300-2000 nm, the wavelength resolution of which is $0.08 \mathrm{~nm}$. The polarized fluorescence spectra and the fluorescence decay curves were measured using an Edinburgh Instruments FLS920 spectrophotometer, the wavelength resolution of which is $0.2 \mathrm{~nm}$. The concentration of $\mathrm{Tm}^{3+}$ ions in the $\mathrm{Tm}^{3+}: \mathrm{Li}_{3} \mathrm{Ba}_{2} \mathrm{Gd}_{3}\left(\mathrm{MoO}_{4}\right)_{8}$ was measured to be 1.26 at $\%$ by the ICP atomic emission spectroscopy analysis method. Thus, the corresponding concentration and the segregation coefficient of $\mathrm{Tm}^{3+}$ ions in the grown crystal were $6.3 \times 10^{-19} \mathrm{~cm}^{2}$ and 0.42 , respectively. All the above measurements were carried out at room temperature.

\section{Results and Discussion}

\subsection{Absorption Spectra and Judd-Ofelt Analysis}

Figure 2 shows the polarized absorption spectra of $\mathrm{Tm}^{3+}: \mathrm{Li}_{3} \mathrm{Ba}_{2} \mathrm{Gd}_{3}\left(\mathrm{MoO}_{4}\right)_{8}$ crystal measured at room temperature. For all polarizations, strong absorption bands occur around 475, 690, 800, 1200, and $1750 \mathrm{~nm}$, corresponding to the transitions of $\mathrm{Tm}^{3+}$ ions from the ground state ${ }^{3} \mathrm{H}_{6}$ to the excited states ${ }^{1} \mathrm{G}_{4},{ }^{3} \mathrm{~F}_{2,3}{ }^{3} \mathrm{H}_{4},{ }^{3} \mathrm{H}_{5}$, and ${ }^{3} \mathrm{~F}_{4}$, respectively. The most attractive band of the absorption spectra is the one around $800 \mathrm{~nm}$, which belongs to the ${ }^{3} \mathrm{H}_{6} \rightarrow{ }^{3} \mathrm{H}_{4}$ transition and is the main pumping channel for $\mathrm{Tm}^{3+}$ ions. The inset of Figure 2 shows the absorption cross-sections $\sigma_{\mathrm{abs}}$ of this band for clarity. As this band is composed of several overlapped peaks, a Lorentz fit was applied to it and three peaks, around 785, 796, and $805 \mathrm{~nm}$, were found. For all polarizations, the peak absorption cross-sections are located at $796 \mathrm{~nm}$ and the values are 4.08, 2.59, and $3.55 \times 10^{-20} \mathrm{~cm}^{2}$ for $\mathrm{E} / / a^{\prime}, \mathrm{E} / / b^{\prime}$, and $\mathrm{E} / / c^{\prime}$, respectively. The full width at half the maximum (FWHM) of the $796 \mathrm{~nm}$ absorption peaks are 9, 11, and $8 \mathrm{~nm}$ for $\mathrm{E} / / a^{\prime}, \mathrm{E} / / b^{\prime}$, and $\mathrm{E} / / c^{\prime}$, respectively, which are close to those of other disordered molybdate crystals, such as $\mathrm{Tm}^{3+}: \mathrm{LiLa}\left(\mathrm{MoO}_{4}\right)_{2}\left(8 \mathrm{~nm}\right.$ for $\sigma$ polarization) [6], $\mathrm{Tm}^{3+}: \operatorname{LiGd}\left(\mathrm{MoO}_{4}\right)_{2}(8 \mathrm{~nm}$ for $\sigma$ polarization) [8], and $\mathrm{Tm}^{3+}: \mathrm{Ba}_{2} \mathrm{Gd}_{4}\left(\mathrm{MoO}_{4}\right)_{4}(7 \mathrm{~nm}$ for $\mathrm{E} / / \mathrm{X}$ and $8 \mathrm{~nm}$ for $\mathrm{E} / / \mathrm{Y})$ [7], but much larger than those of ordered $\mathrm{Tm}^{3+}: \mathrm{YAG}(4 \mathrm{~nm})[1], \mathrm{Tm}^{3+}: \mathrm{YVO}_{4}(5 \mathrm{~nm}$ for $\pi$ polarization) [2], and $\mathrm{Tm}^{3+}: \mathrm{KY}\left(\mathrm{WO}_{4}\right)_{2}\left(5.4 \mathrm{~nm}\right.$ for E// $\left.\mathrm{N}_{\mathrm{m}}\right)$ crystals [3]. Such a broad bandwidth indicates an inhomogeneous broadening behavior of $\mathrm{Tm}^{3+}: \mathrm{Li}_{3} \mathrm{Ba}_{2} \mathrm{Gd}_{3}\left(\mathrm{MoO}_{4}\right)_{8}$ crystal and make the crystal very suitable for diode pumping, as the thermal stabilization of pumping source is not so critical in this case. Furthermore, it can be found that both the profile and the intensity of the absorption bands of $\mathrm{Tm}^{3+}: \mathrm{Li}_{3} \mathrm{Ba}_{2} \mathrm{Gd}_{3}\left(\mathrm{MoO}_{4}\right)_{8}$ are similar to those of the isostructural $\mathrm{Tm}^{3+}: \mathrm{Li}_{3} \mathrm{Ba}_{2} \mathrm{Lu}_{3}\left(\mathrm{MoO}_{4}\right)_{8}$ crystal [16]. 
Figure 2. Polarized absorption spectra of $\mathrm{Tm}^{3+}: \mathrm{Li}_{3} \mathrm{Ba}_{2} \mathrm{Gd}_{3}\left(\mathrm{MoO}_{4}\right)_{8}$ crystal.

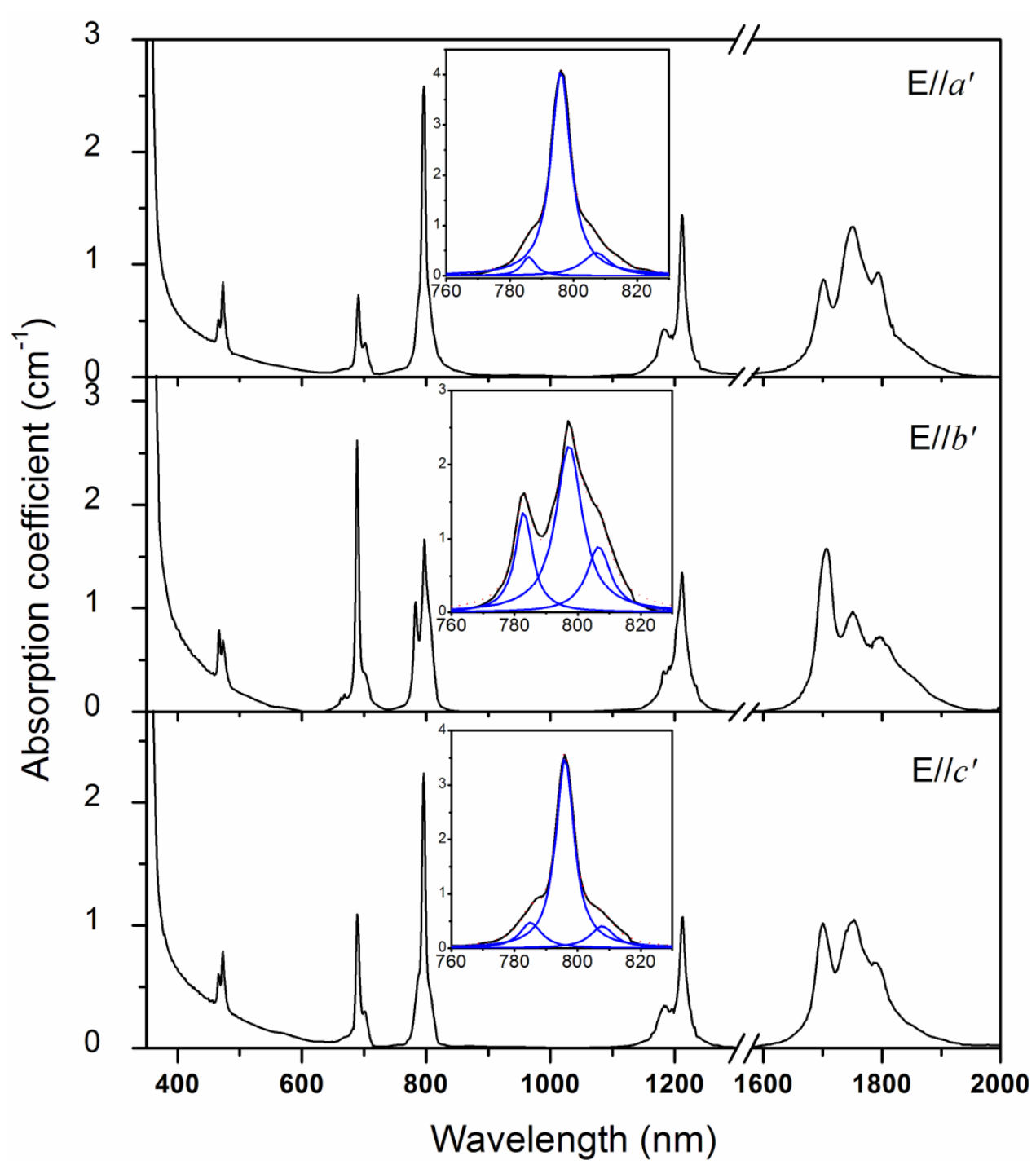

The Judd-Ofelt (J-O) theory has been widely used in the analysis of the spectroscopic properties of rare-earth ions in crystals and glasses $[18,19]$ According the J-O theory, the Judd-Ofelt parameters $\Omega_{\mathrm{t}}$ $(t=2,4,6)$ for each polarization can be calculated by a least-square fitting between the theoretical and the experimental line strengths for the electric-dipole transitions. Then, the spontaneous emission probabilities of the electric-dipole $A^{\text {ed }}$ and magnetic-dipole $A^{\text {md }}$ transitions, the fluorescence branching ratios $\beta$ and the radiative lifetime $\tau_{\mathrm{r}}$ can be estimated. In the present work, only the calculated results are presented, and the detailed calculation procedures are similar to those reported in Reference [4]. The values of the refractive index, $n$, at different wavelengths were calculated using the Sellmeier Equations:

$$
\mathrm{n}^{2}=\mathrm{A}+\frac{\mathrm{B} \lambda^{2}}{\lambda^{2}-\mathrm{C}^{2}}-\mathrm{D} \lambda^{2}
$$

where the constants $A, B, C$, and $D$ for the three polarizations were derived from Reference [17].

The values of $A^{\mathrm{ed}}, A^{\mathrm{md}}, \beta$, and $\tau_{\mathrm{r}}$ of some typical transitions are listed in Table 1 . 
Table 1. The spontaneous emission probabilities, fluorescence branching ratios and radiative lifetimes of $\mathrm{Tm}^{3+}: \mathrm{Li}_{3} \mathrm{Ba}_{2} \mathrm{Gd}_{3}\left(\mathrm{MoO}_{4}\right)_{8}$ crystal.

\begin{tabular}{|c|c|c|c|c|c|c|}
\hline Transitions & $\lambda_{\mathrm{em}}(\mathrm{nm})$ & $\frac{E / / a^{\prime}}{A_{e d}+A_{m d}\left(s^{-1}\right)}$ & $\frac{\mathbf{E} / / \boldsymbol{b}^{\prime}}{\mathbf{A}_{\mathrm{ed}}+\mathbf{A}_{\mathrm{md}}\left(\mathbf{s}^{-1}\right)}$ & $\frac{E / / c^{\prime}}{A_{e d}+A_{m d}\left(s^{-1}\right)}$ & $\boldsymbol{\beta}$ & $\tau_{\mathrm{r}}(\mu \mathbf{s})$ \\
\hline${ }^{1} \mathrm{G}_{4} \rightarrow{ }^{3} \mathrm{H}_{6}$ & 477 & 5035.7 & 5474.1 & 4258.7 & 0.56 & \multirow{6}{*}{113} \\
\hline${ }^{3} \mathrm{~F}_{4}$ & 649 & $345.8+13.8$ & $580.8+13.9$ & $388.7+12.8$ & 0.05 & \\
\hline${ }^{3} \mathrm{H}_{5}$ & 780 & $2031.8+207.2$ & $2334.7+208.7$ & $1936.4+192.4$ & 0.26 & \\
\hline${ }^{3} \mathrm{H}_{4}$ & 1170 & $993.1+47.3$ & $925.3+47.7$ & $839.2+44.03$ & 0.11 & \\
\hline${ }^{3} \mathrm{~F}_{3}$ & 1485 & $93.2+3.8$ & $173.7+3.9$ & $113.2+3.6$ & 0.02 & \\
\hline${ }^{3} \mathrm{~F}_{2}$ & 1635 & 27.9 & 59.8 & 33.4 & 0.004 & \\
\hline${ }^{3} \mathrm{H}_{4} \rightarrow{ }^{3} \mathrm{H}_{6}$ & 785 & 5544.6 & 5597.5 & 4792.5 & 0.90 & \multirow{3}{*}{170} \\
\hline${ }^{3} \mathrm{~F}_{4}$ & 1430 & $469.8+26.8$ & $497.8+27.1$ & $407.2+25$ & 0.08 & \\
\hline${ }^{3} \mathrm{H}_{5}$ & 2165 & $47.9+14$ & $131.5+14.2$ & $62.8+13$ & 0.02 & \\
\hline${ }^{3} \mathrm{H}_{5} \rightarrow{ }^{3} \mathrm{H}_{6}$ & 1225 & $676.0+117$ & $969.5+118$ & $671.6+108.9$ & 0.99 & \multirow{2}{*}{1110} \\
\hline${ }^{3} \mathrm{~F}_{4}$ & 3825 & $12.8+0.16$ & $15.2+0.16$ & $10.9+0.14$ & 0.01 & \\
\hline${ }^{3} \mathrm{~F}_{4} \rightarrow{ }^{3} \mathrm{H}_{6}$ & 1800 & 970.0 & 1040.0 & 791 & 1.00 & 1070 \\
\hline
\end{tabular}

\subsection{Fluorescence Spectra and Emission Cross-Sections}

Figure 3 shows the polarized emission spectra of $\mathrm{Tm}^{3+}: \mathrm{Li}_{3} \mathrm{Ba}_{2} \mathrm{Gd}_{3}\left(\mathrm{MoO}_{4}\right)_{8}$ crystal in a range of 600-1600 nm, when the samples were excited into the ${ }^{1} \mathrm{G}_{4}$ state with $475 \mathrm{~nm}$ radiation. There are four main emission bands around 650, 800, 1175, and $1450 \mathrm{~nm}$ for each polarization. The emission bands around 650,1175 , and $1450 \mathrm{~nm}$ can be assigned to the ${ }^{1} \mathrm{G}_{4} \rightarrow{ }^{3} \mathrm{~F}_{4},{ }^{1} \mathrm{G}_{4} \rightarrow{ }^{3} \mathrm{H}_{4}$, and ${ }^{3} \mathrm{H}_{4} \rightarrow{ }^{3} \mathrm{~F}_{4}$ transitions, respectively. The emission band around $800 \mathrm{~nm}$ should be the superposition of two resonant transitions, namely ${ }^{1} \mathrm{G}_{4} \rightarrow{ }^{3} \mathrm{H}_{5}$ and ${ }^{3} \mathrm{H}_{4} \rightarrow{ }^{3} \mathrm{H}_{6}$, which were severely overlapped due to the very close barycentric wavelengths. To confirm the conclusion, the polarized emission spectra were also measured under $688 \mathrm{~nm}$ excitation, i.e., the $\mathrm{Tm}^{3+}$ ions were excited to the ${ }^{3} \mathrm{~F}_{2,3}$ states. In this case, the ${ }^{3} \mathrm{H}_{4}$ state was populated through non-radiative relaxation from the ${ }^{3} \mathrm{~F}_{2,3}$ states and later on depopulated directly to the ${ }^{3} \mathrm{H}_{6}$ ground state, giving rise the emissions at $800 \mathrm{~nm}$ as shown in Figure 3b. Then, it can be concluded that the weaker emission at $785 \mathrm{~nm}$ in Figure $3 \mathrm{a}$ belongs to the ${ }^{1} \mathrm{G}_{4} \rightarrow{ }^{3} \mathrm{H}_{5}$ transition.

The stimulated emission cross-sections of the ${ }^{3} \mathrm{H}_{4} \rightarrow{ }^{3} \mathrm{~F}_{4}$ transition around $1.5 \mu \mathrm{m}$ were calculated from the fluorescence spectra using the Füchtbauer-Ladenburg(F-L) formula [2]:

$$
\sigma_{e m, q}(\lambda)=\frac{\lambda^{5} A_{q}\left(J \rightarrow J^{\prime}\right) I_{q}(\lambda)}{8 \pi \operatorname{cn}^{2} \int \lambda I_{q}(\lambda) d(\lambda)}
$$

where $\mathrm{c}$ is the speed of light in the vacuum; $\mathrm{I}_{\mathrm{q}}(\lambda)$ is the relative fluorescence intensity at wavelength $\lambda$. Then, the emission cross-sections for three polarizations are shown in Figure 4 . For E//b' the peak emission cross-sections are $1.25 \times 10^{-20} \mathrm{~cm}^{2}$ at $1452 \mathrm{~nm}$. For $\mathrm{E} / / a^{\prime}$ and $\mathrm{E} / / c^{\prime}$, the peak emission cross-sections are located at $1495 \mathrm{~nm}$ and the values are $9.16 \times 10^{-21} \mathrm{~cm}^{2}$ and $1.12 \times 10^{-20} \mathrm{~cm}^{2}$, respectively. The ${ }^{3} \mathrm{H}_{4} \rightarrow{ }^{3} \mathrm{~F}_{4}$ transition of the $\mathrm{Tm}^{3+}$ ions has provided a promising approach to achieve $1.5 \mu \mathrm{m}$ lasers in a more efficient four-level laser operation scheme than $\mathrm{the}^{3+}$ ions. However, their practical applications at this wavelength are inevitably restricted by a detrimental bottlenecking effect 
because the lifetime of the ${ }^{3} \mathrm{~F}_{4}$ state is generally much longer than that of the ${ }^{3} \mathrm{H}_{4}$ state. As a result, to achieve laser operation via ${ }^{3} \mathrm{H}_{4} \rightarrow{ }^{3} \mathrm{~F}_{4}$ transition, some codopants, such as $\mathrm{Ho}^{3+}, \mathrm{Yb}^{3+}$, and $\mathrm{Tb}^{3+}$ should be introduced as deactivator to depopulate the ${ }^{3} \mathrm{~F}_{4}$ state [20].

Figure 3. Polarized fluorescence spectra of $\mathrm{Tm}^{3+}: \mathrm{Li}_{3} \mathrm{Ba}_{2} \mathrm{Gd}_{3}\left(\mathrm{MoO}_{4}\right)_{8}$ crystal: (a) Excited with 473 radiation; (b) Excited with $688 \mathrm{~nm}$ radiation.

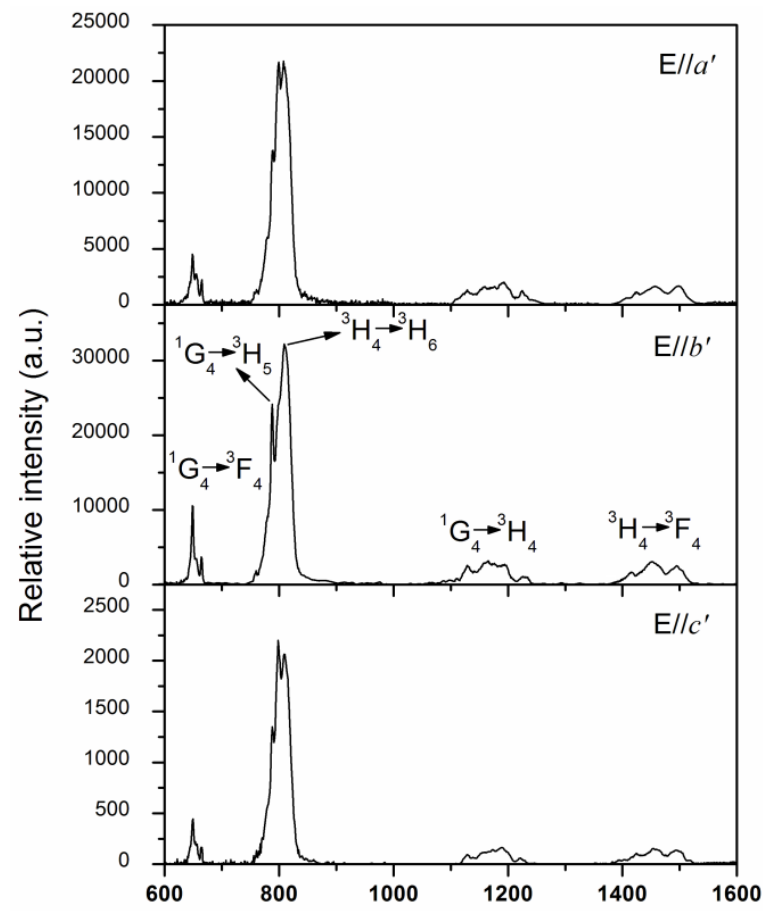

(a)

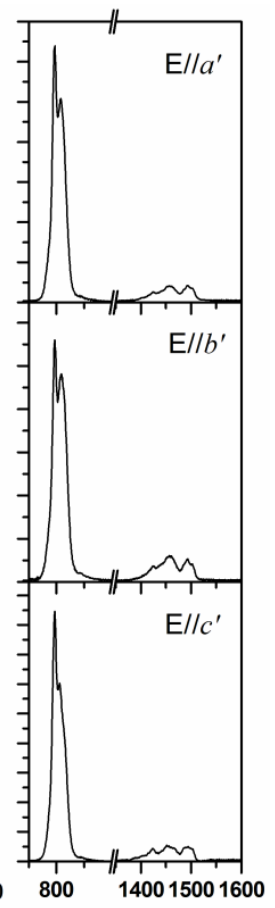

(b)

Wavelength $(\mathrm{nm})$

Figure 4. Polarized emission cross-sections of $\mathrm{Tm}^{3+}: \mathrm{Li}_{3} \mathrm{Ba}_{2} \mathrm{Gd}_{3}\left(\mathrm{MoO}_{4}\right)_{8}$ crystal for the ${ }^{3} \mathrm{H}_{4} \rightarrow{ }^{3} \mathrm{~F}_{4}$ transition around $1.5 \mu \mathrm{m}$.

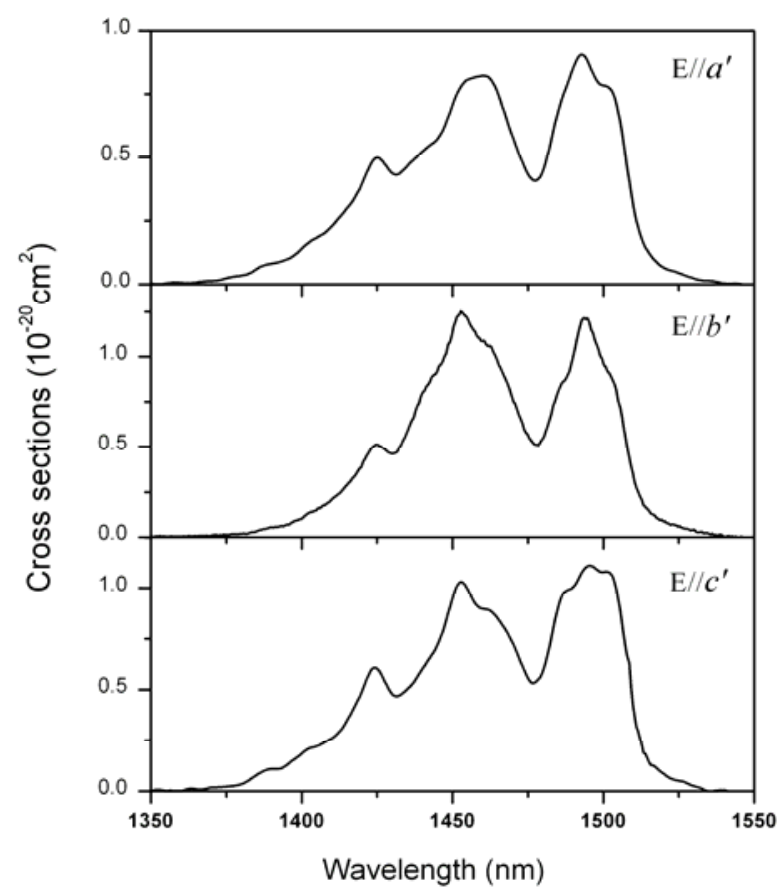


Due to the restriction of the test conditions, only the uncalibrated emission spectra of the ${ }^{3} \mathrm{~F}_{4} \rightarrow{ }^{3} \mathrm{H}_{6}$ transition, around $2 \mu \mathrm{m}$, were obtained, as shown in Figure 5. Thus, the emission cross-sections of this transition were calculated from the absorption spectra according to the reciprocity method [21]:

$$
\sigma_{\mathrm{em}}(\lambda)=\sigma_{\mathrm{abs}}(\lambda) \frac{\mathrm{Z}_{1}}{\mathrm{Z}_{\mathrm{u}}} \exp \left[\left(\mathrm{E}_{\mathrm{zl}}-\mathrm{hc} / \lambda\right) / \mathrm{kT}\right]
$$

where $\mathrm{k}$ is the Boltzmann's constant; $\mathrm{Z}_{1}$ and $\mathrm{Z}_{\mathrm{u}}$ are the partition functions of lower and upper states, respectively; $\mathrm{E}_{\mathrm{zl}}$ is the zero-line energy defined as the energy separation between the lowest Stark levels of the upper and lower multiplets. However, the precise energy level diagram of $\mathrm{Tm}^{3+}$ ions in $\mathrm{Li}_{3} \mathrm{Ba}_{2} \mathrm{Gd}_{3}\left(\mathrm{MoO}_{4}\right)_{8}$ crystal is not available now. Therefore the values of $\mathrm{Z}_{1} / \mathrm{Z}_{\mathrm{u}}$ and $\mathrm{E}_{\mathrm{zl}}$ were roughly taken as $\mathrm{Z}_{\mathrm{l}} / \mathrm{Z}_{\mathrm{u}}=1.42$ and $\mathrm{E}_{\mathrm{zl}}=5600 \mathrm{~cm}^{-1}(0.694 \mathrm{eV})$, respectively, in agreement with those of the isostructural $\mathrm{Tm}^{3+}: \mathrm{Li}_{3} \mathrm{Ba}_{2} \mathrm{Lu}_{3}\left(\mathrm{MoO}_{4}\right)_{8}$ crystal [16]. Then, the emission cross-sections are obtained and listed in Figure 5 combining with the corresponding absorption cross-sections. For all polarizations, the peak emission cross-sections are located at $1796 \mathrm{~nm}$ and the values are $2.38,2.27$, and $2.05 \times 10^{-20} \mathrm{~cm}^{2}$ for $\mathrm{E} / / a^{\prime}, \mathrm{E} / / b^{\prime}$, and $\mathrm{E} / / c^{\prime}$, respectively, which are larger than those of other disordered molybdate crystals (see Table 2). Furthermore, the FWHMs of the emission cross-sections are 133, 154 and $136 \mathrm{~nm}$ for $\mathrm{E} / / a^{\prime}, \mathrm{E} / / b^{\prime}$, and $\mathrm{E} / / c^{\prime}$, respectively, which are similar to those of other disordered molybdate crystals in Table 2 .

Figure 5. Polarized absorption (dot line), emission (solid line) cross-sections and emission spectra (red line) of $\mathrm{Tm}^{3+}: \mathrm{Li}_{3} \mathrm{Ba}_{2} \mathrm{Gd}_{3}\left(\mathrm{MoO}_{4}\right)_{8}$ crystal for the ${ }^{3} \mathrm{~F}_{4} \rightarrow{ }^{3} \mathrm{H}_{6}$ transition.

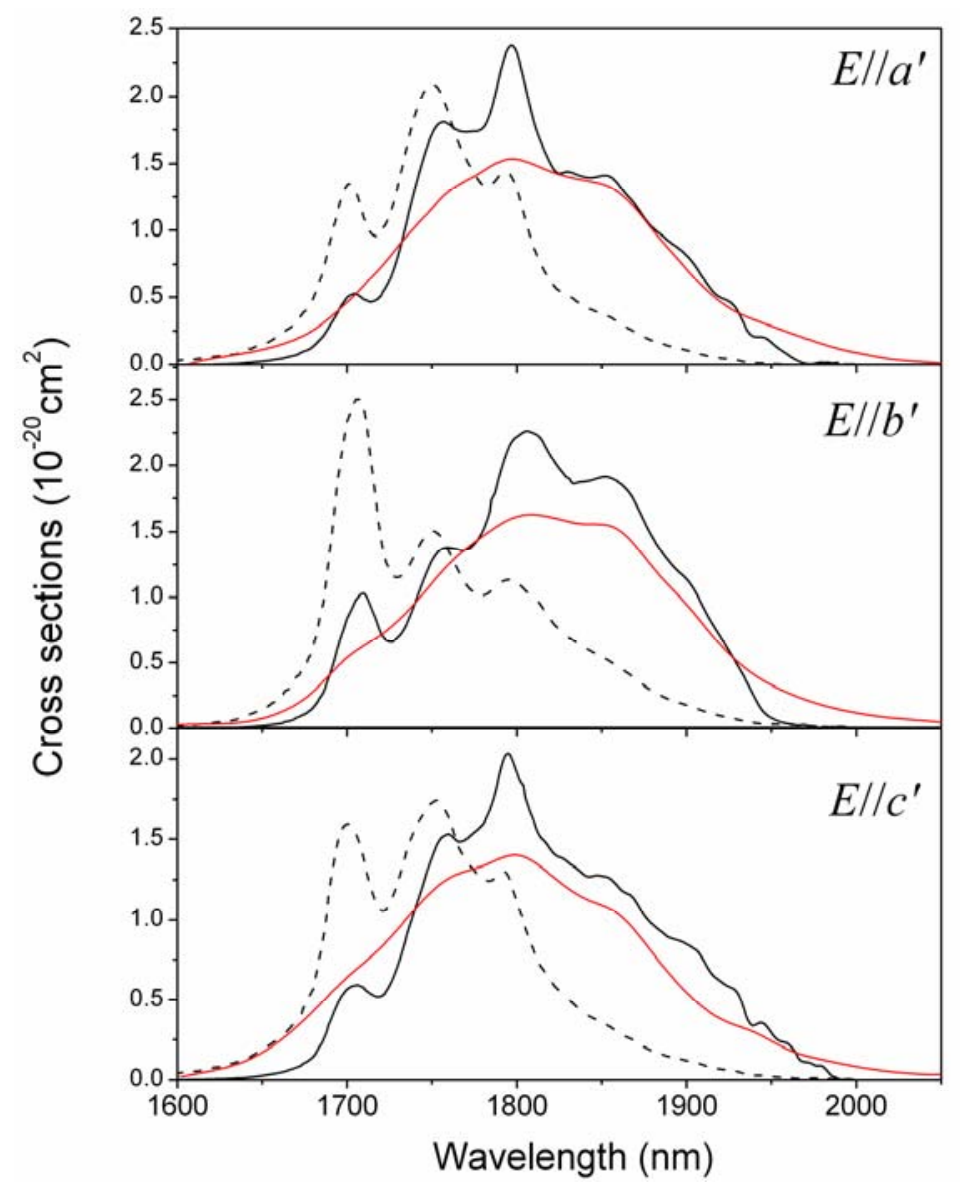


Table 2. The main spectral parameters of $\mathrm{Tm}^{3+}: \mathrm{Li}_{3} \mathrm{Ba}_{2} \mathrm{Gd}_{3}\left(\mathrm{MoO}_{4}\right)_{8}$ and other $\mathrm{Tm}^{3+}$-doped crystals.

\begin{tabular}{|c|c|c|c|c|c|}
\hline Properties & $\mathrm{Li}_{3} \mathrm{Ba}_{2} \mathrm{Gd}_{3}\left(\mathrm{MoO}_{4}\right)_{8}$ & $\mathrm{LiGd}\left(\mathrm{MoO}_{4}\right)_{2}$ & $\operatorname{LiLa}\left(\mathrm{MoO}_{4}\right)_{2}$ & $\mathrm{BaGd}_{2}\left(\mathrm{MoO}_{4}\right)_{4}$ & $\mathrm{Li}_{3} \mathrm{Ba}_{2} \mathrm{Lu}_{3}\left(\mathrm{MoO}_{4}\right)_{8}$ \\
\hline \multirow{3}{*}{$\lambda_{\text {abs }}(\mathrm{nm})$} & 796 & $795(\sigma)$ & 795 & 798 & $797\left(a^{\prime}\right)$ \\
\hline & - & $796(\pi)$ & - & - & $782\left(b^{\prime}\right)$ \\
\hline & - & - & - & - & $804\left(c^{\prime}\right)$ \\
\hline \multirow{3}{*}{$\sigma_{\mathrm{a}}\left(10^{-20} \mathrm{~cm}^{2}\right)$} & $4.08\left(a^{\prime}\right)$ & $4.33(\sigma)$ & $4.04(\sigma)$ & $2.5(\mathrm{X})$ & $3.8\left(a^{\prime}\right)$ \\
\hline & $2.59\left(b^{\prime}\right)$ & $1.59(\pi)$ & $1.53(\pi)$ & $3.5(\mathrm{Y})$ & $2.7\left(b^{\prime}\right)$ \\
\hline & $3.55\left(c^{\prime}\right)$ & - & - & $2.1(\mathrm{Z})$ & $3.1\left(c^{\prime}\right)$ \\
\hline \multirow{3}{*}{ FWHM (nm) } & $9\left(a^{\prime}\right)$ & $8(\sigma)$ & $8(\sigma)$ & $7(\mathrm{X})$ & $8\left(a^{\prime}\right)$ \\
\hline & $11\left(b^{\prime}\right)$ & $37(\pi)$ & $36(\pi)$ & $8(\mathrm{Y})$ & $12\left(b^{\prime}\right)$ \\
\hline & $8\left(c^{\prime}\right)$ & - & - & $17(\mathrm{Z})$ & $8\left(c^{\prime}\right)$ \\
\hline \multirow{3}{*}{$\lambda_{\mathrm{e}}(\mathrm{nm})$} & - & $1786(\sigma)$ & $1787(\sigma)$ & $1800(\mathrm{X})$ & $1800\left(a^{\prime}\right)$ \\
\hline & 1796 & $1838(\pi)$ & $1837(\pi)$ & $1805(\mathrm{Y})$ & $1812\left(b^{\prime}\right)$ \\
\hline & - & - & - & $1819(\mathrm{Z})$ & $1805\left(c^{\prime}\right)$ \\
\hline \multirow{3}{*}{$\sigma_{\mathrm{em}}\left(10^{-20} \mathrm{~cm}^{2}\right)$} & $2.38\left(a^{\prime}\right)$ & $2.44(\sigma)$ & $1.48(\sigma)$ & $1.3(\mathrm{X})$ & $2.65\left(a^{\prime}\right)$ \\
\hline & $2.27\left(b^{\prime}\right)$ & $2.07(\pi)$ & $1.61(\pi)$ & $1.8(\mathrm{Y})$ & $2.30\left(b^{\prime}\right)$ \\
\hline & $2.05\left(c^{\prime}\right)$ & - & - & $1.3(\mathrm{Z})$ & $2.25\left(c^{\prime}\right)$ \\
\hline \multirow{3}{*}{ FWHM (nm) } & $133\left(a^{\prime}\right)$ & $175(\sigma)$ & $143(\sigma)$ & $110(\mathrm{X})$ & $90\left(a^{\prime}\right)$ \\
\hline & $154\left(b^{\prime}\right)$ & $160(\pi)$ & $164(\pi)$ & $84(\mathrm{Y})$ & $168\left(b^{\prime}\right)$ \\
\hline & $136\left(c^{\prime}\right)$ & - & - & $200(Z)$ & $137\left(c^{\prime}\right)$ \\
\hline$\tau_{\mathrm{f}}$ of ${ }^{3} \mathrm{~F}_{4}(\mathrm{~ms})$ & 0.92 & 0.93 & 1.29 & - & 0.97 \\
\hline References & This work & {$[8]$} & {$[6]$} & [7] & {$[16]$} \\
\hline
\end{tabular}

From the absorption and emission cross-sections calculated by the reciprocity method, the gain cross-section, $\sigma_{\mathrm{g}}$, can be calculated according to the following equation:

$$
\sigma_{\mathrm{g}}=\beta \sigma_{\mathrm{em}}-(1-\beta) \sigma_{\mathrm{abs}}
$$

where $\beta$ is the ratio of the number of the excited $\mathrm{Tm}^{3+}$ ions to the total number of $\mathrm{Tm}^{3+}$ ions; $\sigma_{\mathrm{em}}$ and $\sigma_{\text {abs }}$ are the emission and absorption cross-sections, respectively. The calculated gain cross-sections for several values of $\beta$ are shown in Figure 6. According to Figure 6, a minimum inversion ratio of 0.1 is needed to achieve laser operations. For an inversion ratio of $\beta=0.3$, a tunable range wider than $180 \mathrm{~nm}$ is possible for all polarizations.

The fluorescence decay curve of the ${ }^{3} \mathrm{H}_{4}$ and ${ }^{3} \mathrm{~F}_{4}$ state was recorded by monitoring the emissions of the ${ }^{3} \mathrm{H}_{4} \rightarrow{ }^{3} \mathrm{~F}_{4}$ and ${ }^{3} \mathrm{~F}_{4} \rightarrow{ }^{3} \mathrm{H}_{6}$ transitions at 1500 and $1900 \mathrm{~nm}$ under excitation at 800 and $1730 \mathrm{~nm}$, respectively. The decay curve of the ${ }^{3} \mathrm{H}_{4}$ state exhibits a single exponential behavior as shown in Figure 7. The lifetime is obtained to be $153 \mu$ s by linear fitting, which is close to the radiative one. The high quantum efficiency $\eta\left(\tau_{\mathrm{f}} / \tau_{\mathrm{r}}\right)$ of the ${ }^{3} \mathrm{H}_{4}$ state means the cross-relaxation is inefficient in the crystal due to the low $\mathrm{Tm}^{3+}$ concentration. The lifetime of ${ }^{3} \mathrm{~F}_{4}$ state for the bulk crystal is measured to be $1.62 \mathrm{~ms}$ and much larger than the calculated radiative lifetime. Such a large discrepancy is mainly caused by the re-absorption effect, which has been widely observed in $\mathrm{Tm}^{3+}$-doped crystals $[8,16]$. To obtain the intrinsic lifetime of the ${ }^{3} \mathrm{~F}_{4}$ state, the powder method was adopted in this work [22]. A piece of bulk crystal was grounded into fine particles and diluted to a lower concentration of 0.25 at $\%$ $\left(1.25 \times 10^{-19} \mathrm{~cm}^{2}\right)$ with the powder of pure $\mathrm{Li}_{3} \mathrm{Ba}_{2} \mathrm{Gd}_{3}\left(\mathrm{MoO}_{4}\right)_{8}$ crystal. Then, the powder was immersed into ethylene glycol (EG), which was used as refractive index matching fluid to reduce the 
internal reflection within the particles. The fluorescence lifetime of the powder sample was measured to be $0.92 \mathrm{~ms}$, in reasonable agreement with the radiative one calculated by the J-O theory.

Figure 6. Gain cross-sections of $\mathrm{Tm}^{3+}: \mathrm{Li}_{3} \mathrm{Ba}_{2} \mathrm{Gd}_{3}\left(\mathrm{MoO}_{4}\right)_{8}$ crystal for different values of inversion ratio $\beta(\beta=0.1,0.2,0.3,0.4,0.5)$.

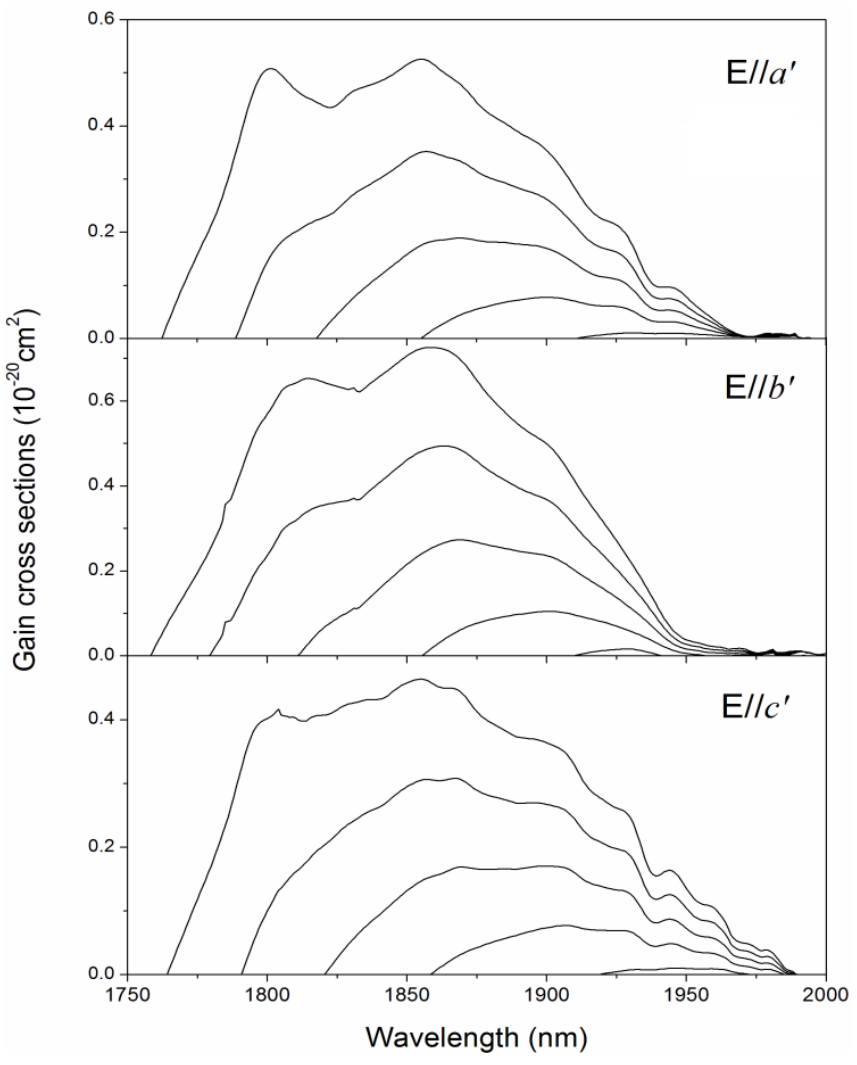

Figure 7. Fluorescence decay curves of ${ }^{3} \mathrm{H}_{4}$ and ${ }^{3} \mathrm{~F}_{4}$ state.

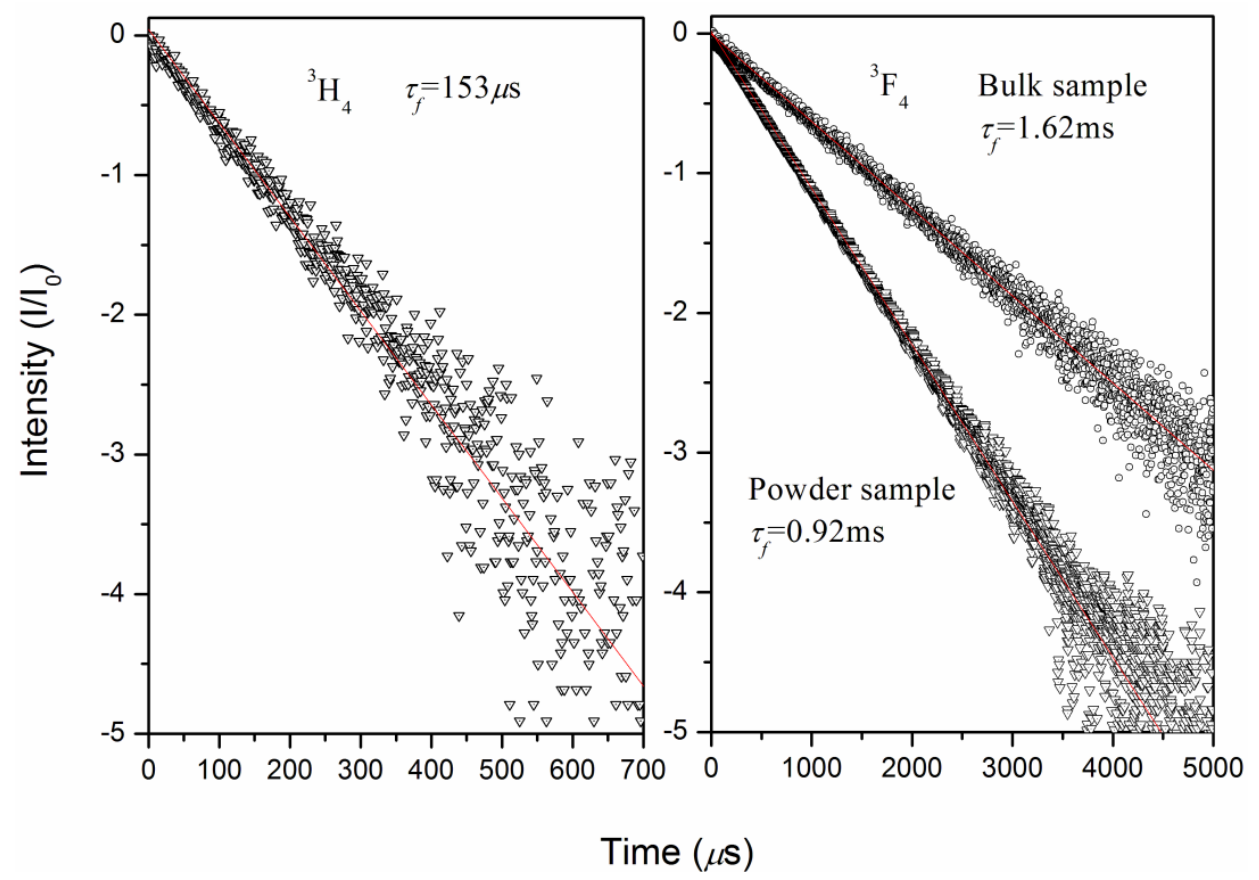




\section{Conclusions}

A $\mathrm{Tm}^{3+}: \mathrm{Li}_{3} \mathrm{Ba}_{2} \mathrm{Gd}_{3}\left(\mathrm{MoO}_{4}\right)_{8}$ crystal has been successfully grown by the top seeded solution growth (TSSG) method, and the detailed spectral properties of the crystal were characterized and investigated on the basis of the J-O theory. The main spectral parameters of the crystal are listed in Table 2 and compared with other $\mathrm{Tm}^{3+}$-doped crystals. It can be found that $\mathrm{Tm}^{3+}: \mathrm{Li}_{3} \mathrm{Ba}_{2} \mathrm{Gd}_{3}\left(\mathrm{MoO}_{4}\right)_{8}$ crystal possesses similar spectral characters to other disordered molybdate crystals, i.e., all of them exhibited broad optical bands, large absorption and emission cross-sections, as well as long lifetimes of ${ }^{3} \mathrm{~F}_{4}$ state. In summary, the main spectroscopic parameters of the $\mathrm{Tm}^{3+}: \mathrm{Li}_{3} \mathrm{Ba}_{2} \mathrm{Gd}_{3}\left(\mathrm{MoO}_{4}\right)_{8}$ crystal are comparable to those of the $\mathrm{Tm}^{3+}: \mathrm{Li}_{3} \mathrm{Ba}_{2} \mathrm{Lu}_{3}\left(\mathrm{MoO}_{4}\right)_{8}$ crystal. As a consequence, in view of the excellent laser performance of the $\mathrm{Tm}^{3+}: \mathrm{Li}_{3} \mathrm{Ba}_{2} \mathrm{Lu}_{3}\left(\mathrm{MoO}_{4}\right)_{8}$ crystal [16], we may expect the $\mathrm{Tm}^{3+}: \mathrm{Li}_{3} \mathrm{Ba}_{2} \mathrm{Gd}_{3}\left(\mathrm{MoO}_{4}\right)_{8}$ crystal to be a potential solid state laser material at $\sim 2.0 \mu \mathrm{m}$.

\section{Acknowledgments}

This work was supported by the Natural Science Foundation of Shandong Province (ZR2010BL011) and the Science Foundation of Weifang University.

\section{Conflicts of Interest}

The authors declare no conflict of interest.

\section{References}

1. Fan, T.Y.; Huber, G.; Byer, R.L.; Mitzscherlich, P. Spectroscopy and diode laser-pumped operation of Tm,Ho:YAG. IEEE J. Quantum Electron. 1988, 24, 924-933.

2. Ohta, K.; Saito, H.; Obara, M. Spectroscopic characterization of $\mathrm{Tm}^{3+}: \mathrm{YVO}_{4}$ crystal as an efficient diode pumped laser source near 2000 nm. J. Appl. Phys. 1993, 73, 3149-3153.

3. Troshin, A.E.; Kisel, V.E.; Yasukevich, A.S.; Kuleshov, N.V.; Pavlyuk, A.A.; Dunina, E.B.; Kornienko, A.A. Spectroscopy and laser properties of $\mathrm{Tm}^{3+}: \mathrm{KY}\left(\mathrm{WO}_{4}\right)_{2}$ crystal. Appl. Phys. B 2007, 86, 287-292.

4. Guo, W.J.; Chen, Y.J.; Lin, Y.F.; Luo, Z.D.; Gong, X.H.; Huang, Y.D. Spectroscopic properties and laser performance of $\mathrm{Tm}^{3+}$-doped $\mathrm{NaLa}\left(\mathrm{MoO}_{4}\right)_{2}$ crystal. J. Appl. Phys. 2008, 103, 093106:1-093106:10.

5. Han, X.M.; Cano-Torres, J.M.; Rico, M.; Cascales, C.; Zaldo, C.; Mateos, X.; Rivier, S.; Griebner, U.; Petrov, V. Spectroscopy and efficient laser operation near $1.95 \mu \mathrm{m}$ of $\mathrm{Tm}^{3+}$ in disordered $\mathrm{NaLu}\left(\mathrm{WO}_{4}\right)_{2}$. J. Appl. Phys. 2008, 103, 083110:1-083110:8.

6. Wei, Y.W.; Chen, Y.J.; Lin, Y.F.; Gong, X.H.; Luo, Z.D.; Huang, Y.D. Spectral properties of $\mathrm{Tm}^{3+}$-doped LiLa( $\left(\mathrm{MoO}_{4}\right)_{2}$ crystal. J. Alloy. Compd. 2009, 484, 529-534.

7. Zhu, H.M.; Chen, Y.J.; Lin, Y.F.; Gong, X.H.; Luo, Z.D.; Huang, Y.D. Spectral properties and efficient laser operation near $2.0 \mu \mathrm{m}$ of $\mathrm{Tm}^{3+}: \mathrm{BaGd}_{2}\left(\mathrm{MoO}_{4}\right)_{4}$ crystal. J. Opt. Soc. Am. B 2008, 25, 801-809. 
8. Tang, J.F.; Chen, Y.J.; Lin, Y.F.; Gong, X.H.; Huang, J.H.; Luo, Z.D.; Huang, Y.D. Polarized spectral properties and laser demonstration of $\mathrm{Tm}^{3+}$-doped $\mathrm{LiGd}\left(\mathrm{MoO}_{4}\right)_{2}$. J. Opt. Soc. Am. B 2010, 27, 1769-1777.

9. Lagatsky, A.A.; Calvez, S.; Gupta, J.A.; Kisel, V.E.; Kuleshov, N.V.; Brown, C.T.A.; Dawson, M.D.; Sibbett, W. Broadly tunable femtosecond mode-locking in a Tm:KYW laser near $2 \mu \mathrm{m}$. Opt. Express 2011, 19, 9995-10000.

10. Koopmann, P.; Peters, R.; Petermann, K.; Huber, G. Crystal growth, spectroscopy, and highly efficient laser operation of thulium-doped $\mathrm{Lu}_{2} \mathrm{O}_{3}$ around $2 \mu \mathrm{m}$. Appl. Phys. B 2011, 102, 19-24.

11. Batay, L.E.; Demidovich, A.A.; Kuzmin, A.N.; Ryabtsev, G.I.; Strek, W.; Titov, A.N. Passive Q-switching of laser diode pumped LBGM:Nd Laser. Spectrochim. Acta A 1998, 54, 2117-2120.

12. García-Cortés, A.; Cascales, C. Crystal growth and optical and spectroscopic characterization of the ytterbium-doped laser molybdate $\mathrm{Yb}-\mathrm{Li}_{3} \mathrm{Gd}_{3} \mathrm{Ba}_{2}\left(\mathrm{MoO}_{4}\right)_{8}$. Chem. Mater. 2008, 20, 3884-3891.

13. García-Cortés, A.; Zaldo, C.; Cascales, C.; Mateos, X.; Petrov, V. Laser operation of $\mathrm{Yb}^{3+}$ in disordered $\mathrm{Li}_{0.75} \mathrm{Gd}_{0.75} \mathrm{Ba}_{0.5}\left(\mathrm{MoO}_{4}\right)_{2}$ crystal with small quantum defect. Opt. Express 2007, 15, 18162:1-18162:7.

14. Song, M.J.; Zhao, W.; Wang, G.F.; Zhao, M.L.; Wang, L.T. Growth, thermal and polarized spectral properties of $\mathrm{Nd}^{3+}$-doped $\mathrm{Li}_{3} \mathrm{Ba}_{2} \mathrm{Gd}_{3}\left(\mathrm{MoO}_{4}\right)_{8}$ crystal. J. Alloy. Compd. 2011, 509, 2164-2169.

15. Song, M.J.; Wang, L.T.; Zhao, W.; Wang, G.F.; Zhao, M.L.; Meng, Q.G. Growth and spectroscopic properties of $\mathrm{Er}^{3+}$-doped $\mathrm{Li}_{3} \mathrm{Ba}_{2} \mathrm{Y}_{3}\left(\mathrm{MoO}_{4}\right)_{8}$ crystal. Mater. Sci. Eng. B 2011, 176, 810-815.

16. Rico, M.; Han, X.M.; Cascales, C.; Esteban-Betegón, F.; Zaldo, C. Efficient mid-infrared laser operation of $\mathrm{Li}_{3} \mathrm{Lu}_{3-\mathrm{x}} \mathrm{Tm}_{\mathrm{x}} \mathrm{Ba}_{2}\left(\mathrm{MoO}_{4}\right)_{8}$ disordered crystal. Opt. Express 2011, 19, 7640-7645.

17. Han, X.M.; Calderón-Villajos, R.; Esteban-Betegón, F.; Cascales, C.; Zaldo, C. Crystal growth and physical characterization of monoclinic $\mathrm{Li}_{3} \mathrm{Lu}_{3} \mathrm{Ba}_{2}\left(\mathrm{MoO}_{4}\right)_{8}$ : A spectrally broadened disordered crystal for ultrafast mode-locked lasers. Cryst. Growth Des. 2012, 12, 3878-3887.

18. Judd, B.R. Optical absorption intensities of rare-earth ions. Phys. Rev. 1962, 127, 750-761.

19. Ofelt, G.S. Intensities of crystal spectra of rare-earth ions. J. Chem. Phys. 1962, 37, 511-520.

20. Braud, A.; Girard, S.; Doualan, J.L.; Moncorgé, R. Spectroscopy and fluorescence dynamics of $\left(\mathrm{Tm}^{3+}, \mathrm{Tb}^{3+}\right)$ and $\left(\mathrm{Tm}^{3+}, \mathrm{Eu}^{3+}\right)$ doped $\mathrm{LiYF}_{4}$ single crystals for 1.5- $\mu \mathrm{m}$ laser operation. IEEE $J$. Quantum Electron. 1998, 34, 2246-2255.

21. McCumber, D.E. Einstein relations connecting broadband emission and absorption spectra. Phys. Rev. 1964, 136, A954-A957.

22. Pujol, M.C.; Bursukova, M.A.; Güell, F.; Mateos, X.; Solé, R.; Gavaldà, J.; Aguiló, M.; Massons, J.; Díaz, F.; Klopp, K.; et al. Growth, optical characterization, and laser operation of a stoichiometric crystal KYb($\left(\mathrm{WO}_{4}\right)_{2}$. Phys. Rev. B 2002, 65, 165121:1-165121:11.

(C) 2014 by the authors; licensee MDPI, Basel, Switzerland. This article is an open access article distributed under the terms and conditions of the Creative Commons Attribution license (http://creativecommons.org/licenses/by/3.0/). 